\title{
Skirining fitokimia ekstrak etanol kulit buah sirsak (Annona muricata Linn) dan uji aktivitas antioksidan dengan metode DPPH
}

\author{
Nur Alim ${ }^{*}$, Nurul Jummah ${ }^{1}$, Agus Sangka Pratama ${ }^{1}$, Nurdiyanti ${ }^{1}$ \\ 1 Prodi S1 Farmasi, Fakultas MIPA, Universitas Islam Makassar, Makassar, Indonesia.
}

DOI: $\underline{\text { https://doi.org/10.29303/sjp.v2i2.40 }}$

Article Info

Received : 2020-07-11

Revised : :2021-04-29

Accepted : 2021-08-09

\begin{abstract}
Phytochemical screening research on the ethanol extract of soursop (Annona muricata Linn) peel and antioxidant activity was tested using the DPPH method. The purpose of this study was to determine several classes of compounds found in soursop rind and to determine the antioxidant activity of ethanol extract of soursop rind against DPPH free radicals. The results showed ethanol extract of positive soursop fruit skin containing flavonoids, tannins, and terpenoids. of soursop fruit skin extract was carried out by DPPH method results obtained IC50 value of $192.13 \mu \mathrm{g} / \mathrm{mL} \pm 5.198137$ which was categorized as weak.
\end{abstract}

Keywords: Phytochemical screening, Annona muricata Linn, antioxidant activity, DPPH

\begin{abstract}
Citation : Alim, N., Jummah, J., Pratama, A.S., \& Nurdiyanti. (2021). Skirining fitokimia ekstrak etanol kulit buah sirsak (Annona muricata Linn) dan uji aktivitas antioksidan dengan metode DPPH. Sasambo Journal of Pharmacy, 2(2), 60-64. https:// doi.org/10.29303/sjp.v2i2.40
\end{abstract}

\section{Pendahuluan}

Obat dapat dikatakan sebagai radikal bebas dengan pengertian bahwa suatu obat tersebut mengandung senyawa atau molekul yang memiliki satu atau lebih elektron tidak berpasangan. Elektron yang tidak berpasangan menyebabkan senyawa tersebut sangat reaktif mencari pasangan, dengan cara menyerang dan mengikat elektron molekul yang berada disekitarnya. Radikal bebas sangat berbahaya dikarenakan tingginya reaktivitas yang mengakibatkan terbentuknya senyawa radikal baru. Senyawa radikal baru tersebut terbentuk apabila bertemu dengan molekul lain dan seterusnya hingga terjadi reaksi berantai (Hidayat, 2007).

Radikal bebas dapat dijumpai pada lingkungan, asap rokok, polusi udara, obat, bahan beracun, makanan dalam kemasan, bahan adiktif dan sinar ultraviolet yang menyebabkan radiasi. Reaktivitas radikal bebas dapat dihambat oleh sistem antioksidan yang merupakan bagian dari sistem kekebalan tubuh (Wijaya, 1996).
Antioksidan merupakan bahan atau senyawa yang dapat menghambat atau mencegah terjadinya oksidasi. Antioksidan dikelompokkan menjadi dua berdasarkan sumbernya, yaitu antioksidan alami dan antioksidan sintetik. Tubuh manusia memproduksi antioksidan secara alami, namun jika terjadi paparan radikal bebas yang berlebih, maka tubuh membutuhkan antioksidan yang berasal dari luar tubuh (Muhilal, 1991).

Antioksidan alami merupakan jenis antioksidan yang berasal dari tumbuhan dan hewan. Adapun contoh dari antioksidan alami adalah tokoferol, asam askorbat, komponen fenolik, turunan senyawa hidroksinat, kuramin (Purwaningsih, 2012).

Antioksidan sintetik sangat efektif dalam menghambat reaksi oksidasi lemak, akan tetapi penggunaan antioksidan sintetik banyak menimbulkan kekhawatiran akan efek sampingnya karena telah banyak penelitian tentang efek patologis yang ditimbulkannya (Purwaningsih, 2012). Antioksidan sintetik yang diijinkan dan umum digunakan untuk makanan yaitu Butylated Hydroyanisole (BHA), Butylated 
Hydroxytoluene (BHT). Profil galat dan tokoferol (Purwaningsih, 2012).

Penggunaan antioksidan sintetik mulai dibatasi karena dari hasil penelitian menyatakan bahwa antioksidan sintetik seperti Butylated Hydroxytoluene (BHT) dapat meracuni binatang percobaan dan bersifat karsinogenik (Zuhra, 2008). Telah dilaporkan bahwa penggunaan antioksidan sintetik seperti BHA dapat menimbulkan akibat buruk terhadap kesehatan manusia yaitu gangguan fungsi hati, paru, mukosa usus dan keracunan (Panagan, 2011).

Menurut penelitian yang dilakukan Baskar dan Kumar (2007) berjudul In Vitro Antioxidant Studies In Leaves Of Annona Spesies, didapatkan hasil bahwa daun sirsak mengandung senyawa flavonoid dan memiliki aktivitas antioksidan yang sangat kuat dengan nilai $\mathrm{IC}_{50} 70 \mathrm{ppm}$.

\section{Metode}

\section{Alat dan Bahan}

Alat-alat yang digunakan adalah rotary evaporator, cawan porselin, gelas ukur, labu tentukur, mikropipet (Eppendorf), rotary evaporator, rak tabung, spektrofotometer (Thermo), tabung reaksi, timbangan analisis (Ohaus), wadah maserasi, vortex (Branstead) dan pipet tetes

Bahan-bahan yang digunakan adalah air suling, asam asetat, asam klorida, asam sulfat pekat, etanol $96 \%$, etanol $70 \%$, simplisia kulit buah sirsak, pereaksi Dragendorf, pereaksi Mayer, kloroform, besi (III) klorida, serbuk magnesium, metanol p.a,vitamin C.

\section{Pengolahan Sampel}

Bagian sampel yang digunakan yaitu kulit buah sirsak. Kulit buah sirsak tersebut kemudian dicuci dengan air yang mengalir sampai bersih, lalu dipotongpotong kecil. Kemudian dikeringkan dengan cara diangin-anginkan, selanjutnya diserbukkan dan diekstraksi denagn menggunakan etanol $96 \%$ dengan menggunakan metode maserasi.

\section{Ekstraksi sampel}

Sampel kulit buah sirsak ditimbang sebanyak 340 gram kemudian dimasukkan ke dalam wadah maserasi, sampel dibasahi terlebih dahulu dengan etanol $96 \%$ lalu ditambahkan etanol $96 \%$ sebanyak 1200 $\mathrm{mL}$ (hingga simplisia tersebut terendam) dan dibiarkan selama 5 hari dan diaduk-aduk sekali-sekali setiap hari. Kemudian disaring dengan menggunakan kertas whatman dan ampasnya dimaserasi kembali dengan pelarut yang sama, remaserasi dilakukan sampai dua kali. Ekstrak cair dipekatkan menggunakan rotary evaporator. Ekstrak etanol kental disimpan dalam desikator dan ditimbang untuk mengetahui berat rendemennya.

\section{Pembuatan Pereaksi}

\section{a. Pereaksi Dragendroff}

Untuk pereaksi Dragendroff dibuat dalam dua larutan yaitu: Larutan (I) 0,85 gram bismutsubnitrat dilarautkan dalam $40 \mathrm{~mL}$ air dan $10 \mathrm{~mL}$ asam asetat sedangkan larutan (II) 8,0 gram kalium iodida dilarutkan dalam $20 \mathrm{~mL}$ air. Setiap $5 \mathrm{~mL}$ larutan (I) dan (II) dicampur $20 \mathrm{~mL}$ asam asetat dan dicukupkan dengan aquadest hingga $100 \mathrm{~mL}$ (Autherhoff, 2002).

b. Pereaksi Mayer

Sebanyak 1,35 g raksa (II) klorida dilarutkan dalam $100 \mathrm{~mL}$ larutan kalium iodida 5\% (Autheroff, 2002).

\section{Skrining Fitokimia}

\section{a. Uji Alkaloid}

Sebanyak $100 \mathrm{mg}$ ekstrak dilarutkan dengan 5 mL HCL 2 N. Larutan yang diperoleh dibagi ke dalam 2 tabung reaksi. Tabung pertama ditambahkan 3 tetes pereaksi Dragendroff dan tabung kedua ditambahkan 3 tetes pereaksi Mayer.Terbentuk endapan jingga pada tabung pertama dan endapan kuning pada tabung kedua menunjukkan adanya alkaloid (Farsnworth, 1966).

b. Uji Flavanoid

Sebanyak $100 \mathrm{mg}$ ditambahkan $2 \mathrm{~mL}$ etanol lalu kocok hingga homogen ditambahkan kemudian ditambahkan serbuk $\mathrm{Mg}$ dan 5 tetes $\mathrm{HCl}$ pekat. Bila terbentuk warna merah, kuning atau jingga ini menunjukan adanya flavanoid (Harborne, 1987).

c. Uji saponin.

Sebanyak $100 \mathrm{mg}$ ekstrak dimasukkan dalam tabung reaksi dan ditambahkan $2 \mathrm{~mL}$ air panas, lalu kocok selama 10 detik. Jika terbentuk buih yang stabil selama \pm 10 menit setinggi 1-2 cm (Ciulei, 1984).

d. Uji Terpenoid

Sebanyak $100 \mathrm{mg}$ ekstrak dimasukkan dalam tabung reaksi lalu ditambahkan $2 \mathrm{~mL}$ etanol $70 \%$ dan diaduk. Ditambahkan $1 \mathrm{~mL}$ kloroform dalam tabung reaksi lalu ditambahkan $1 \mathrm{~mL}$ asam asetat anhidrat, didinginkan lalu ditambahkan asam sulfat pekat melalui dinding tabung. Reaksi positif jika hasil menunjukan adanya cincin kecoklatan atau violet pada perbatasan dua pelarut maka ekstrak dinyatakan positif mengandung terpenoid (Ciulei, 1984).

e. Uji Tanin

Sebanyak $100 \mathrm{mg}$ ekstrak ditambahkan $2 \mathrm{~mL}$ air lalu diaduk dan ditambahkan 3 tetes $\mathrm{FeCl}_{3}$. Adanya tanin ditandai dengan pembentukan biru atau hijau kehitaman (Farsnworth, 1966). 


\section{Uji Aktivitas Antioksidan}

1. Pembuatan LarutanDifenil-Pikrilhidrazil (DPPH)

Larutan DPPH 0,4 mM dibuat dengan cara menimbang DPPH sebanyak 0,0157 gram dilarutkan dalam labu tentukur 100 mL menggunakan metanol p.a hingga tanda batas.

\section{Pengukuran Aktivitas Radikal Bebas DPPH}

DPPH 0,4 mM dibuat dengan cara dipipet $1 \mathrm{~mL}$ larutan DPPH dan dimasukkan dalam labu tentukar 5 $\mathrm{mL}$ yang dibungkus dengan aluminium foil kemudian dicukupkan volumenya dengan metanol p.a hingga 5 $\mathrm{mL}$ lalu didiamkan selama 30 menit. Selanjutnya diukur absorbansinya menggunakan spektrofotometri visibel pada panjang gelombang $500 \mathrm{~nm}$.

Pembuatan Larutan Baku Kulit Buah Sirsak 1000 pRm

Ditimbang $10 \mathrm{mg}$ ekstrak kulit buah sirsak dilarutkan dengan pelarut metanol p.a sambil dihomogenkan lalu dimasukkan ke dalam labu tentukur dan dicukupkan volumenya dengan metanol p.a hingga $10 \mathrm{~mL}$, sebagai larutan stock 1000 ppm.

\section{Hasil dan Pembahasan}

Tabel 1. Hasil perhitungan rendamen ekstrak etanol kulit buah sirsak (Annona muricata Linn)

\begin{tabular}{ccccc} 
Sampel & $\begin{array}{c}\text { Berat } \\
\text { Sampel } \\
(\mathbf{g})\end{array}$ & $\begin{array}{c}\text { Volume } \\
\text { Pelarut } \\
(\mathbf{m L})\end{array}$ & $\begin{array}{c}\text { Berat } \\
\text { Ekstrak } \\
(\mathbf{g})\end{array}$ & $\begin{array}{c}\text { Persen } \\
\text { Rendamen } \\
(\mathbf{\%})\end{array}$ \\
\hline $\begin{array}{c}\text { Kulit } \\
\text { buah } \\
\text { sirsak }\end{array}$ & 340 & 1200 & 37,15 & 10,92 \\
\hline
\end{tabular}

Tabel 2. Hasil identifikasi golongan senyawa yang terkandung dalam ekstrak etanol kulit buah sirsak (Annona muricata Linn)

\begin{tabular}{|c|c|c|c|c|}
\hline \multirow{2}{*}{$\begin{array}{l}\text { Golongan } \\
\text { Senyawa }\end{array}$} & \multirow{2}{*}{$\begin{array}{l}\text { Nama } \\
\text { Reaksi }\end{array}$} & \multicolumn{2}{|c|}{ Hasil } & \multirow{2}{*}{ Ket } \\
\hline & & Teori & Pengamatan & \\
\hline \multirow{2}{*}{ Alkaloid } & Dragendorf & $\begin{array}{l}\text { Endapan } \\
\text { Jingga }\end{array}$ & $\begin{array}{l}\text { Warna } \\
\text { Coklat }\end{array}$ & $(-)$ \\
\hline & Mayer & $\begin{array}{c}\text { Endapan } \\
\text { kuning }\end{array}$ & $\begin{array}{l}\text { Warna } \\
\text { Coklat }\end{array}$ & $(-)$ \\
\hline Flavonoid & $\begin{array}{c}\text { Etanol+Se } \\
\text { rbuk } \\
\mathrm{Mg}+\mathrm{HCl} \\
\mathrm{P} \\
\end{array}$ & $\begin{array}{l}\text { Warna } \\
\text { Merah, } \\
\text { Jingga, } \\
\text { Kuning } \\
\end{array}$ & $\begin{array}{l}\text { Warna } \\
\text { Merah }\end{array}$ & $(+)$ \\
\hline Saponin & Uji Buih & $\begin{array}{c}\text { Buih yang } \\
\text { stabil selama } \\
\pm 10 \text { menit } \\
\text { setinggi } 1-2 \\
\text { cm }\end{array}$ & $\begin{array}{l}\text { Terbentuk } \\
\text { buih } 1 \mathrm{~cm}, \\
\text { tidak stabil }\end{array}$ & $(-)$ \\
\hline Terpenoid & $\begin{array}{c}\text { Etanol } \\
70 \%+\text { Klor } \\
\text { oform+As } \\
\text { am Asetat } \\
\text { Anhidrat } \\
+ \\
\mathrm{H}_{2} \mathrm{SO}_{4}\end{array}$ & $\begin{array}{c}\text { Cincin } \\
\text { kecoklatan/ } \\
\text { Violet }\end{array}$ & $\begin{array}{l}\text { Cincin } \\
\text { Kecoklatan }\end{array}$ & $(+)$ \\
\hline Tanin & $\mathrm{FeCl}_{3}$ & $\begin{array}{l}\text { Biru/Hijau } \\
\text { Kehitaman }\end{array}$ & $\begin{array}{c}\text { Hijau } \\
\text { kehitaman }\end{array}$ & $(+)$ \\
\hline
\end{tabular}

Pengukuran Aktivitas Antioksidan Ekstrak Kulit Buah Sirsak dengan Metode DPPH

Pengujian aktivitas ekstrak Kulit Buah Sirsak sebagai antioksidan dilakukan dengan memipet larutan stock 1000 ppm masing-masing 0,1 mL, 0,2 mL, 0,4 mL, $0,8 \mathrm{~mL}$, dan 1,6 mL dimasukkan ke dalam labu tentukur 5 mLyang dibungkus dengan aluminium foil blu ditambahkan 1,0 mL DPPH 0,4 mM dan dicukupkan volumenya dengan metanol p.a hingga $5 \mathrm{~mL}$, diperoleh konsentrasi 20 ppm, 40 ppm, 80 ppm, 160 ppm dan 320 ppm. Didiamkan selama 30 menit, selanjutnya serapannya diukur dengan spektrofotometri visibel pada panjang gelombang $500 \mathrm{~nm}$.

$$
4
$$

\section{Pembuatan dan Pengukuran Aktivitas Antioksidan} Larutan Pembanding Vitamin C

Larutan Vitamin C 1000 ppm dibuat dengan cara menimbang sebanyak $10 \mathrm{mg}$ vitamin $\mathrm{C}$ dilarutkan dengan metanol p.a sambil dihomogenkan, lalu dicukupkan volumenya dengan metanol p.a hingga 10 mL. Larutan 1000 ppm kemudian diencerkan menjadi $100 \mathrm{ppm}$. Untuk pengujian aktivitas antioksidanlarutan vitamin $\mathrm{C}$ dilakukan dengan memipet larutan stock 100 ppm masing-masing $0,05 \mathrm{~mL}, 0,1 \mathrm{~mL}, 0,15 \mathrm{~mL}, 0,2$ $\mathrm{mL}$, dan 0,25 $\mathrm{mL}$ lalu ditambahkan DPPH 0,4 $\mathrm{mM} 1$ $\mathrm{mL}$, dicukupkan volumenya sampai $5 \mathrm{~mL}$ dengan metanol p.a dalam labu tentukur yang dibungkus dengan aluminium foil, sehingga diperoleh konsentrasi 1 ppm, 2 ppm, 3 ppm, 4 ppm dan 5 ppm. Ditutup dan didiamkan selama 30 menit. Selanjutnya serapannya diukur dengan alat spektrofotometri visibel pada panjang gelombang $500 \mathrm{~nm}$.
Tabel 3. Aktivitas Antioksidan Ekstrak Etanol Kulit Buah Sirsak (Annona muricata Linn) dengan metode DPPH (Replikasi 1)

\begin{tabular}{cccc}
\hline $\begin{array}{c}\text { Konsentrasi } \\
(\mathbf{p p m})\end{array}$ & $\begin{array}{c}\text { Absorbansi } \\
(\mathbf{n m})\end{array}$ & $\begin{array}{c}\text { Aktivitas } \\
\text { Antioksidan } \\
(\%)\end{array}$ & $\begin{array}{c}\text { Nilai } \\
\text { IC50 } \\
(\mu \mathrm{g} / \mathbf{m L})\end{array}$ \\
\hline 20 & 0,502 & 3,46 & \\
\cline { 1 - 2 } & 0,472 & 10,27 & \\
\cline { 1 - 2 } & $0,396,16$ & \\
& & 24,90 &
\end{tabular}


320

0,153

70,91

Kontrol

0,526

Tabel 4. Aktivitas Antioksidan Ekstrak Etanol Kulit Buah Sirsak (Annona muricata Linn) dengan metode DPPH (Replikasi 2)

\begin{tabular}{|c|c|c|c|}
\hline $\begin{array}{l}\text { Konsentrasi } \\
\quad(\mathrm{ppm})\end{array}$ & $\begin{array}{l}\text { Absorbansi } \\
\text { (nm) }\end{array}$ & $\begin{array}{c}\text { Aktivitas } \\
\text { Antioksidan } \\
(\%) \\
\end{array}$ & $\begin{array}{c}\text { Nilai } \mathrm{IC}_{50} \\
(\mu \mathrm{g} / \mathrm{mL})\end{array}$ \\
\hline 20 & 0,439 & 5,99 & \multirow{6}{*}{195,63} \\
\hline 40 & 0,413 & 11,56 & \\
\hline 80 & 0,355 & 23,98 & \\
\hline 160 & 0,254 & 45,61 & \\
\hline 320 & 0,105 & 77,52 & \\
\hline Kontrol & 0,467 & & \\
\hline
\end{tabular}

Tabel 5. Aktivitas Antioksidan Ekstrak Etanol Kulit Buah Sirsak (Annona muricata Linn) dengan metode DPPH (Replikasi 3)

\begin{tabular}{|c|c|c|c|}
\hline $\begin{array}{l}\text { Konsentrasi } \\
\quad(\mathrm{ppm})\end{array}$ & $\begin{array}{l}\text { Absorbansi } \\
\text { (nm) }\end{array}$ & $\begin{array}{c}\text { Aktivitas } \\
\text { Antioksidan } \\
(\%) \\
\end{array}$ & $\begin{array}{c}\text { Nilai IC50 } \\
(\mu \mathrm{g} / \mathrm{mL})\end{array}$ \\
\hline 20 & 0,426 & 7,39 & \multirow{6}{*}{194,61} \\
\hline 40 & 0,403 & 12,39 & \\
\hline 80 & 0,346 & 24,78 & \\
\hline 160 & 0,255 & 44,57 & \\
\hline 320 & 0,101 & 78,04 & \\
\hline Kontrol & 0,460 & & \\
\hline
\end{tabular}

Tabel 6. Hasil Rata-Rata Nilai IC 50 Ekstrak Kulit Buah Sirsak (Annona muricata Linn)

\begin{tabular}{ccc}
\hline Pengujian & $\begin{array}{c}\text { Nilai IC50 } \\
(\boldsymbol{\mu g} / \mathbf{m L})\end{array}$ & $\begin{array}{c}\text { Rata-Rata } \pm \\
\text { Simpangan Baku }\end{array}$ \\
\hline Replikasi 1 & 186,16 & \\
Replikasi 2 & 195,63 & \multirow{2}{1}{$192,13 \pm 5,198137$} \\
\hline Replikasi 3 & 194,61 & \\
\hline
\end{tabular}

Tabel 7. Hasil Pengukuran Aktivitas Antioksidan Larutan Pembanding Vitamin C

\begin{tabular}{|c|c|c|c|}
\hline $\begin{array}{c}\text { Konsentrasi } \\
(\text { ppm) }\end{array}$ & $\begin{array}{l}\text { Absorbansi } \\
\quad(\mathrm{nm})\end{array}$ & $\begin{array}{c}\text { Aktivitas } \\
\text { Antioksidan } \\
(\%)\end{array}$ & $\begin{array}{l}\text { Nilai IC } 50 \\
(\mu \mathrm{g} / \mathrm{mL})\end{array}$ \\
\hline 1 & 0,279 & 38,14 & \multirow{6}{*}{1,84} \\
\hline 2 & 0,22 & 51,22 & \\
\hline 3 & 0,149 & 66,96 & \\
\hline 4 & 0,076 & 83,15 & \\
\hline 5 & 0,014 & 96,90 & \\
\hline Kontrol & 0,451 & & \\
\hline
\end{tabular}

\section{PEMBAHASAN}

Skrining fitokimia merupakan suatu metode pengujian awal dalam upaya untuk mengetahui kandungan senyawa aktif yang terdapat dalam tumbuhan. Skrining fitokimia pada pengujian ini bertujuan untuk mengetahui adanya golongan senyawa alkaloid, flavanoid, saponin, terpenoid dan tanin pada kulit buah sirsak.

Identifikasi alkaloid, suatu senyawa dinyatakan positif mengandung alkaloid yaitu terbentuknya endapan jingga pada penambahan pereaksi Dragendroff dan endapan kuning pada penambahan pereaksi Mayer (Farnswoth, 1996). Identifikasi senyawa flavanoid dinyatakan positif bila terbentuk warna merah, kuning atau jingga (Harborne, 1987). Identifikasi senyawa saponin ditandai dengan terbentuknya buih yang stabil selama \pm 10 menit setinggi $1-2 \mathrm{~cm}$. Senyawa terpenoid reaksi positif jika hasil menunjukan adanya cincin kecoklatan atau violet pada perbatasan dua pelarut (Ciulei, 1984). Senyawa tanin dinyatakan positif bila terbentuk warna biru kehitaman dan hijau kehitaman. Berdasarkan hasil identifikasi yang telah dilakukan diperoleh data bahwa ekstrak kulit buah sirsak mengandung senyawa golongan flavanoid, terpenoid, dan tanin.

Uji aktivitas antioksidan pada ekstrak kulit buah sirsak (Annona muricata Linn) dilakukan dengan metode DPPH menggunakan spektrofotometer visible pada panjang gelombang $500 \mathrm{~nm}$. Metode DPPH digunakan karena merupakan metode yang sederhana, mudah, dan menggunakan sampel dalam jumlah yang sedikit dengan waktu yang singkat (Hanani, dkk, 2005). Senyawa DPPH menerima elektron akan membentuk senyawa yang stabil. Interaksi antioksidan dengan DPPH baik secara transfer elektron pada DPPH, akan menetralkan karakter radikal bebas dari DPPH. Metanol p.a digunakan sebagai pelarut karena dapat melarutkan Kristal DPPH (Molyneux, 2004). Metanol juga cenderung lebih murah dibandingkan dengan pelarut yang lainnya. Adanya aktivitas antioksidan dari sampel mengakibatkan perubahan warna dari larutan DPPH dalam metanol yang semula berwarna violet pekat menjadi kuning (Andayani, dkk, 2008).

Parameter yang digunakan untuk menunjukkan aktivitas antioksidan adalah inhibitory consentration $\left(\mathrm{IC}_{50}\right)$ yaitu konsentrasi suatu zat antioksidan yang dapat menyebabkan 50\% DPPH kehilangan karakter atau konsentrasi suatu zat antioksidan yang memberikan persen penghambatan 50\% (Molyneux, 2004). Semakin kecil nilai $\mathrm{IC}_{50}$ berarti aktivitas antioksidannya semakin tinggi.

Hasil analisis data menunjukkan bahwa ekstrak etanol kulit buah sirsak (Annona muricata Linn) dengan 
nilai $\mathrm{IC}_{50}$ adalah sebesar 192,13 $\mu \mathrm{g} / \mathrm{mL}$. Berdasarkan nilai $\mathrm{IC}_{50}$ yang diperoleh aktivitas ekstrak etanol kulit buah sirsak dikategorikan lemah (Molyneux, 2004).

\section{Kesimpulan}

Berdasarkan hasil penelitian dan pembahasan dapat disimpulkan bahwa:

1. Ekstrak etanol kulit buah sirsak (Annona muricata Linn) mengandung beberapa golongan senyawa yaitu flavonoid, terpenoid, dan tanin.

2. Pengujian aktivitas antioksidan ekstrak etanol kulit buah sirsak memiliki nilai IC 50 $_{0}$ sebesar 192,13 $\mu \mathrm{g} / \mathrm{mL} \pm$ 5,198137 yang dikategorikan lemah.

Penelitian selanjutnya sebaiknya dilakukan penelitan menggunakan ekstrak fraksi.

\section{Daftar Pustaka}

Andayani, R., Maimunah, M., \& Lisawati, Y. (2008). Penentuan aktivitas antioksidan, kadar fenolat total dan likopen pada buah tomat (Solanum lycopersicum L.). Jurnal Sains dan Teknologi Farmasi, 13(1), 31-37. http://repo.unand.ac.id/2221/

Autherhoff, H., \& Kovar, K. (2002). Identifikasi obat (N.C. Sugiarso, Trans). Penerbit ITB. (Original work published 1987)

Baskar, R., Rajeswari, V., \& Kumar, T. S. (2007). In vitro antioxidant studies in leaves of Annona spesies. Indian J Exp Biol., 45(5), 480-485. https://pubmed.ncbi.nlm.nih.gov/17569293/

Ciulei, J. (1984). Methodology for analysis of vegetables drugs. Bucharest. Faculty of pharmacy Rumania. http://www.download.portal.garuda.org.pdf.

Farsnworth, N. R. (1966). Biological and phytochemical screening of plant. Journal of Pharmaceutical Sciences, 55(3), 225-276. https://ipharmsci.org/article/S00223549(15)35305-3/pdf

Hanani, E., Mun'im, A., dan Sekarini, R. (2005). Identifikasi senyawa antioksidan dalam spons Callyspongia sp. dari Kepulauan Seribu. Majalah Ilmu Kefarmasian, 2(3), 127-133. http://journal.ui.ac.id/index.php/mik/article/v iew/1150/1057

Harborne, J. B. (1987). Metode fitokimia (2nd ed.). Institut Teknologi Bandung.
Hidajat, B. (2005). Penggunaan antioksidan pada anak. Kapita Selekta Ilmu Kesehatan Anak. Jakarta.

Molyneux, P. (2004). The use of the stable free radical diphenylpicrylhydrazyl (DPPH) for estimating antioxidant activity. Songklanakarin J. Sci. Technol., 26(2), 211-219. https://www.thaiscience.info/journals/Article/ SONG/10462423.pdf

Muhilal, M. (1991). Teori radikal bebas dalam gizi dan kedokteran. Cermin Dunia Kedokteran, 73, 9-11.

Panagan, A. T., Yohandini, H., \& Gultom, J.U. (2011). Analisis kualitatif dan kuantitatif asam lemak tak jenuh omega 3 dari minyak ikan patin (Pangasius pangasius) dengan metoda kromatografi gas. Jurnal Penelitian Sains, 14(4), 38-42. http:// ejurnal.mipa.unsri.ac.id/index.php/jps/a $\underline{\text { rticle/view/204/195 }}$

Purwaningsih, S. (2012). Aktivitas antioksidan dan komposisi kimia keong matah merah (Cerithidea obtusa). Indonesian Journal of Marine Sciences, 17(1),39-48. DOI:10.14710/ik.ijms.17.1.39-48

Wijaya, A. (1996). Radikal bebas dan parameter status antioksidan. Prodia Diagnostic Educational Services. Jakarta.

Zuhra, C. F., Tarigan, J. B., \& Sihotang, H. M. (2010). Aktivitas antioksidan senyawa flavonoid dari daun katuk (Sauropus androgunus (L) Merr.). Jurnal Biologi Sumatera, 3(1), 7-10. https://www.semanticscholar.org/paper/Aktiv itas-Antioksidan-Senyawa-Flavonoid-DariDaun-ZuhraTarigan/80dce8da8d62d16864af019784c8610e403 $\underline{4 c 972}$ 